FACULTY OF ECONOMICS AND APPLIED ECONOMIC SCIENCES

CENTER FOR ECONOMIC STUDIES

ENERGY, TRANSPORT \& ENVIRONMENT

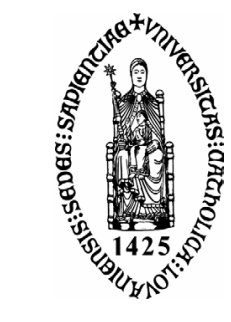

KATHOLIEKE UNIVERSITEIT LEUVEN

WORKING PAPER SERIES

$n^{\circ}$ 2004-16

\title{
Multi Pollutant Yardstick Schemes as Environmental Policy Tools
}

Laurent Franckx (Department of Economics and

Management, Royal Military

Academy)

Alessio D'Amato (University of Rome "Tor Vergata")

Isabelle Brose (Department of Economics and Management, Royal Military Academy)

November 2004

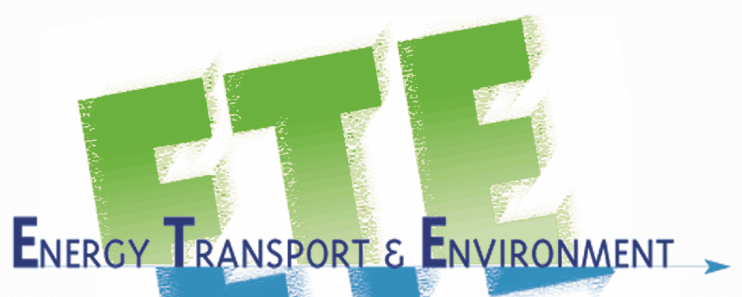

secretariat:

Isabelle Benoit

KULeuven-CES

Naamsestraat 69, B-3000 Leuven (Belgium)

tel: $\quad+32(0) 1632.66 .33$

fax: $\quad+32(0) 1632.69 .10$

e-mail: Isabelle.Benoit@econ.kuleuven.ac.be

http://www.kuleuven.be/ete 


\title{
Multi Pollutant Yardstick Schemes as Environmental Policy Tools
}

\author{
Laurent Franckx ${ }^{*}$ Alessio D’Amato ${ }^{\dagger}$ Isabelle Brose ${ }^{\ddagger}$
}

November 25, 2004

\begin{abstract}
We consider environmental regulation of $n$ risk-averse, multiple pollutant firms. We develop a "yardstick competition" scheme where the regulatory scheme depends on the difference between a firm's "aggregate" performance and the average "aggregate" performance of the industry. Whether this instruments dominates Pigovian taxation depends on the complete structure of the covariance matrix of the "common" random terms in measured pollution. Moreover, if the number of firms is large enough, the "yardstick scheme" is always superior to Pigovian taxation. This analysis also provides new arguments in favor of strict liability rather than negligence liability as regulatory tool.

Keywords: yardstick competition, multitasking, environmental regulation, asymmetric information

Acknowledgments: The authors benefited from their interaction with participants at the 9th European Spring Meeting of Young Economists, at the Annual Conference of the European Association of Environmental and Resource Economists 2004, at the 19th Annual Congress of the European Economic Association and at the CORE Workshop on Industrial Economics and the Environment (28-29 October 2004). Special thanks go to Partha Dasgupta, Pierre Fleckinger and Juan-Pablo Montero for their insightful comments and suggestions.
\end{abstract}

\footnotetext{
${ }^{*}$ Corresponding author: Department of Economics and Management, Royal Military Academy, Avenue de la Renaissance 30, 1000 Bruxelles, Belgium, Tel: 00/32/(0)2.737.64.57, Fax: 00/32/(0)2.737.65.12, e-mail: Laurent.Franckx@rma.ac.be

†University of Rome "Tor Vergata", Via Columbia, 2; 00133, Rome, Italy; tel. +3906 72595927; fax: +39 06 2040219; e-mail:damato@economia.uniroma2.it

${ }^{\ddagger}$ Department of Economics and Management, Royal Military Academy, Avenue de la Renaissance 30, 1000 Bruxelles, Belgium, Tel: 00/32/(0)2.737.64.57, Fax: 00/32/(0)2.737.65.12, e-mail: Isabelle.Brose@rma.ac.be
} 


\section{Introduction}

This paper proposes a model of "yardstick competition" for the regulation of multi-pollutant firms.

In a system of "yardstick competition", the transfers to an economic agent (here: a polluting firm) do not only depend on his own performance, but also on the performance of some reference group determined by the principal (here: the environmental regulator). Holmstrom [7, Theorem 8] has shown how the use of peer performance allows to "filter out" stochastic shocks that are common to all considered agents, and thus to obtain incentive schemes that - for the same incentive effects - impose less risk on the agents than schemes that are based on their own performance only. More specifically, Holmstrom shows that, under some relatively mild assumptions, the optimal incentive scheme should depend on the agent's own performance and a weighted average of the peer group's performance only.

Schleifer [19] has initiated the application of this type of scheme to a regulatory context. However, applications of "yardstick competition" seem to focus on the regulation of natural monopolies (see the celebrated work by Laffont and Tirole [10] or, for a more recent example, Tangerȧs [21] ), while the literature on environmental regulation has paid relatively little attention to the potential and drawbacks of this type of regulatory instruments.

One exception is the analysis by Govindasamy et.al. [2], who show how rank based incentive mechanisms (or tournaments) can be used as environmental policy tool. Tournaments were introduced by Lazear and Rosen [12] as incentive schemes in labor contracts. In a tournament, the transfer to the regulated agent only depends on the ranking of his performance relative to other agents, rather then on the absolute values of these performances - tournaments are thus a very specific type of "relative performance" incentive scheme. The main conclusion gained by Govindasamy et.al. is that, when firms subject to environmental regulation are risk neutral, tournaments share with emission taxes the ability of achieving a first-best outcome. To the best of our knowledge, the paper by Govindasamy et.al. has not been followed by generalizations or applications.

The purpose of this paper is to apply a slightly different incentive scheme to a more general context.

The distinctive features of our model are the following.

First, we make use of a "relative performance" scheme of the type proposed by Holmstrom [7], rather than of tournaments. Arguably, the most important advantage of tournaments is indeed their reduced informational needs as compared to those of other incentive mechanisms: the principal has, in fact, only to observe "relative" performances of each agent rather than their "absolute" performance. Hence, tournaments use ordinal rather than cardinal information. However, if cardinal information is observable (as is the case with the emissions of polluting firms), then tournaments will never be optimal. This has been shown independenly by Mookherjee [14, Proposition 4] and Holmstrom [7, Theorem 8]. Of course, as emphasized for instance by Holmstrom, these results in themselves do not show that the particular scheme we propose corresponds 
to the global optimum. However, it is easy to verify that the "relative performance" scheme developed in this paper dominates for instance the multi-task tournament discussed in Franckx et.al. [5].

The second issue we focus on is related to the multi task nature of emissions abatement performed by regulated firms. Indeed, most production activities cause the discharge of more than one kind of pollutants in the environment. One example could be point water pollution due to sewage treatment plants: a properly shaped policy intervention would require the environmental regulator in charge of water quality to account for B.O.D. (Biochemical Oxygen Demand) emissions as well as for discharges of other toxic substances, such as mercury. The same is true for pulp and paper industry, that in different stages of the production process can cause emissions of BOD, SO2 and toxic chemicals, such as dioxins. A final example can be nitrogen and phosphorus emissions from the use of fertilizers in agriculture.

Govindasamy et.al. [2] underline the multidimensional nature of pollution reducing effort levels, but they do not address the related modeling problems, simply suggesting the use of an aggregate index as a measure of polluting firms' effort. ${ }^{1}$

Our approach here has thus been inspired by the multi task principal/agent analysis performed by Holmstrom and Milgrom [8]: Holmstrom and Milgrom extend the standard principal/agent model to allow for multidimensional tasks to be performed by workers, and, inter alia, provide an explanation for real-world phenomena such as missing incentive clauses in contracts and "low-powered" incentives in firms.

The third issue of our analysis is the introduction of risk aversion. Risk and uncertainty can indeed be crucial in environmental policy design, as the performance of different pollution control instruments might be severely affected by difficulties related to emissions measurement or stochastic impacts on ambient pollution. In the case of small, owner-operated business, the assumption of risk aversion is certainly not far-fetched. As Holmstrom and Milgrom underline, incentive mechanisms "...serve the dual function of allocating risk and rewarding productive work" [8, p. 25]. However in Govindasamy et.al. [2], regulated firms are risk neutral, so that no conflict among efficiency and risk "insurance" arises (which explains why they obtain first best results).

A fourth innovation is that we consider more general production and abatement technologies: contrary to Govindasamy et.al., we do not assume that production and abatement decisions are separable, or that there is a single input in abatement.

Finally, Govindasamy et.al. impose a very specific form of budget balancing where expected gross social benefits from pollution abatement are re-distributed to regulated firms via the regulatory scheme. We think it is more realistic to assume that the incentive schemes are paid out of (or contribute to) the general

\footnotetext{
${ }^{1}$ Note that this multi task nature of regulation is not limited to environmental regulation. For instance, in their celebrated work on regulation, Laffont and Tirole point out that "concern has been expressed about the effects of yardstick competition on cost. It is feared that firms would concentrate their efforts on reducing cost and would sacrifice quality." [10, p. 212].
} 
budget of the government, which is financed out of distortionary taxation.

Starting from these arguments, we model a situation where risk averse firms subject to environmental policy emit several pollutants. We assume that emissions are subject to stochastic influences (or measurement errors). These stochastic influences can be split in terms that are firm-specific (or idiosyncratic) and terms that are identical across firms (from now, we shall call these "common" terms). Thus, contrary to what is usually investigated in the literature on "yardstick competition", we consider a problem of moral hazard (hidden action) and not adverse selection (hidden information).

We then develop a multi-task "yardstick" instrument rewarding the firm according to the difference between their "aggregate" performance and the average "aggregate" performance of all the regulated firms. In this scheme, the environmental regulator chooses the weights assigned to each pollutant in determining aggregate performance of each firm. We show that, with risk averse firms, optimal emission levels depend on the number of firms, on the technical relationship between output and emissions, and on the covariance matrix of the common error terms.

We show subsequently that the "yardstick competition" scheme dominates Pigovian taxes if (1) the variance of at least one common random term is high enough or (2) if the covariance between different common error terms is high enough. While the first point is a generalization of a point that is well known in a one-dimensional setting, the second point is a new contribution. Moreover, we show that if the number of firms is high enough, "yardstick competition" always dominates Pigovian taxation.

Our work also provides insights in the debate concerning the choice of "environmental" liability rules, as an alternative to direct pollution regulation. Specifically, we provide an argument in favor of strict liability when pollution control involves performing multiple tasks, some of which cannot be contracted upon.

The paper is organized as follows. Section 2 presents the model. In Section 3, we derive the main features of a relative performance incentive scheme. Section 4 analyzes the properties of emission taxes. In Section 5, we compare the relative welfare properties of the two proposed environmental policy tools. In Section 6, we show that the insights from the analysis of yardstick competition in a multidimensional setting help to understand some fundamental problems related to negligence liability. Finally, Section 7 concludes and suggests directions for future research.

\section{The Model}

We model a regulatory context where an environmental protection agency is in charge of environmental quality in a certain region.

There are $n$ firms $i=1, \ldots, n .{ }^{2}$ These firms produce a homogenous output

\footnotetext{
${ }^{2}$ With a given number of firms, there are no entry/exit issues but we do have to consider participation constraints.
} 
$q_{i}$. $q_{i}$ is sold at a market price $p$. In order to remain consistent with the assumption that firms are risk averse, we suppose they are "small" and thus price-takers.

The firms also generate a verifiable vector of emissions $\boldsymbol{e}_{\boldsymbol{i}} \equiv\left(e_{i 1} \ldots e_{i j} \ldots e_{i J}\right)$. Total emissions for pollutant $j$ are $e_{j}=\sum_{i=1}^{n} e_{i j}$ and the vector of total emissions is $\boldsymbol{e} \equiv \sum_{i=1}^{n} \boldsymbol{e}_{\boldsymbol{i}}$.

Observed emissions are $e_{i j}=s_{i j}+\eta_{j}^{e}+\epsilon_{i j}^{e}$, where $s_{i j}$, expected emissions, are a choice variable for the firms. The $\eta_{j}^{e}$ and $\epsilon_{i j}^{e}$ are stochastic terms, which can be interpreted both as genuine random influences and as measurement errors. The $\eta_{j}^{e}$ are common across firms while the $\epsilon_{i j}^{e}$ are firm-specific.

$\eta_{j}^{e}$ follows a normal law with zero mean and covariance matrix $\Sigma_{\eta}$. The $\epsilon_{i j}^{e}$ follow a normal law with zero mean and covariance matrix $\Sigma_{\epsilon}$. The common shocks and the idiosyncratic shocks are independently distributed. Therefore, the covariance matrix of the sum of the two stochastic terms is simply the sum of the individual covariance matrices $\Sigma=\Sigma_{\epsilon}+\Sigma_{\eta}$.

Let $\boldsymbol{s}_{\boldsymbol{i}} \equiv\left(s_{i 1} \ldots s_{i j} \ldots s_{i J}\right)$.

The cost function associated with an output $q_{i}$ and an expected emission vector $\boldsymbol{s}_{\boldsymbol{i}}$ will be denoted $C\left(q_{i}, \boldsymbol{s}_{\boldsymbol{i}}\right)$ - we assume thus that firms are identical and that their cost function is common knowledge. Of course, we assume that $\frac{\partial C(.)}{\partial s_{i j}}<0$.

As there is no stochasticity in production, unregulated profits are:

$$
\Pi_{i}(.) \equiv p q_{i}-C\left(q_{i}, \boldsymbol{s}_{\boldsymbol{i}}\right) .
$$

The regulator requires the firms to engage in pollution abatement activity. We define "abatement" in a broad sense, including actions such as output reduction, scrubbers installation and so on.

We shall make no assumption with respect to the verifiability of the inputs used in production and abatement. We shall just assume that, for some reason, the regulator is constrained not to base its regulatory scheme on inputs or outputs. $^{3}$

We assume that each firm $i$ 's has constant absolute risk aversion, measured by a parameter $\rho$, and has mean-variance preferences. If $w_{i}$ is a payment whose precise value depends on the chosen pollution control instrument ${ }^{4}$, then the firm's expected utility function is:

$$
\Pi_{i}(\cdot)+E\left(w_{i}\right)-\frac{1}{2} \rho \mathbf{v a r}\left(w_{i}\right) ;
$$

\footnotetext{
${ }^{3}$ Actually, it can be shown that, in general, it is optimal to combine emission based mechanisms with input based mechanisms if firms are risk averse. However, with multiple pollutants, the results become quickly intractable - full details of this argument can be obtained from the authors on request.

${ }^{4}$ In general, under uncertainty the firms' preferences are expected to depend also on moments of the error terms' distributions different from the mean and the variance. As a consequence the mean-variance functional form we propose in the text is intended to be an approximation. See Hirshleifer and Riley [6] for a discussion, and Laffont and Tirole [9] for an application in a regulatory context.
} 
Finally, expected social costs from pollution are given by: $E(D(\boldsymbol{e}))$. Note that this formulation takes into account that there might be externalities between the different pollutants.

\section{Linear yardstick competition}

We model, in this section, a $n$-player yardstick competition scheme.

Before the "game" takes place, the regulator commits to the weights given to each outcome in determining the "overall performance" of each player; call this weight $\gamma_{j}$ for net emissions $e_{i j}$.

"Overall observed performance" for player $i$ will, therefore, be (where $\gamma=$ $\left(\gamma_{1} \ldots \gamma_{j} \ldots \gamma_{J}\right)$ and $\cdot$ is the inner product of two vectors):

$$
\gamma \cdot e_{i}
$$

Player $k$ receives (or pays) the following compensation scheme:

$$
w_{0}-\gamma \cdot\left(e_{k}-\frac{1}{n} \sum_{i=1}^{n} e_{i}\right)
$$

Our aim is to determine the optimal fixed wage $w_{0}$ and a set of "performance weights" $\gamma_{j}$. To do this, we first derive abatement strategies by the firms, given an arbitrary value for $w_{0}$ and an arbitrary level for the $\gamma_{j} s$.

Thus, let us first turn to the firms' problem.

First, note that $\boldsymbol{\gamma} \cdot\left(\boldsymbol{e}_{\boldsymbol{k}}-\frac{1}{n} \sum_{i=1}^{n} \boldsymbol{e}_{\boldsymbol{i}}\right)$ can be developed to

$$
\boldsymbol{\gamma} \cdot\left(s_{k}-\frac{1}{n} \sum_{i=1}^{n} s_{i}+\left(\epsilon_{k}-\frac{1}{n} \sum_{i=1}^{n} \epsilon_{i}\right)\right) .
$$

We can therefore conclude that yardstick competition is indeed capable of sorting out common error terms.

Hence, firm $k$ 's expected regulatory transfer is:

$$
w_{0}-\gamma \cdot\left(s_{k}-\frac{1}{n} \sum_{i=1}^{n} s_{i}\right)
$$

while the variance of this transfer is

$$
\frac{n-1}{n} \gamma \Sigma_{\epsilon} \gamma^{T}
$$

Therefore, the certainty equivalence of firm $k$ 's expected utility is:

$$
w_{0}-\boldsymbol{\gamma} \cdot\left(s_{\boldsymbol{k}}-\frac{1}{n} \sum_{i=1}^{n} s_{i}\right)+p q_{k}-C\left(q_{k}, s_{\boldsymbol{k}}\right)-\frac{1}{2} \frac{n-1}{n} \rho \boldsymbol{\gamma} \Sigma_{\epsilon} \boldsymbol{\gamma}^{T}
$$


Agent's $k$ FOCs w.r.t. $q_{k}$ are

$$
\frac{\partial \Pi}{\partial q_{k}}=0
$$

If all emission levels induced by the incentive scheme are strictly positive, then agent's $k$ FOCs w.r.t. $s_{k j}$ are

$$
\frac{\partial \Pi}{\partial s_{k j}}=\frac{n-1}{n} \gamma_{j},
$$

If the firms are identical, then the FOC for the other players will be symmetric.

We limit our attention to symmetric Nash equilibria.

Let us simplify notation. Let $\Pi_{s}^{\prime} \equiv\left(\frac{\partial \Pi(.)}{\partial s_{1}} \ldots \frac{\partial \Pi(.)}{\partial s_{J}}\right)$. The FOC with respect to the emissions can then be expressed as follows (where from now on we leave the index of the firm) in matrix form:

$$
\Pi_{s}^{\prime}=\frac{n-1}{n} \gamma
$$

Let us now turn to the regulator's problem.

The total regulatory transfer is

$$
n w_{0}-\sum_{k=1}^{n}\left(\gamma \cdot\left(\boldsymbol{e}_{\boldsymbol{k}}-\frac{1}{n} \sum_{i=1}^{n} \boldsymbol{e}_{\boldsymbol{i}}\right)\right)=n w_{0} .
$$

This shows that the total transfer is a constant. Hence, the principal does not gain from filing false reports on observed performance, which is an important drawback of the credibility of incentive schemes based on individual performance (see for instance Malcomson [13]).

We assume that these regulatory transfers are financed out of distortionary taxation.

If the firms are price takers, then we can ignore consumer surplus. Moreover, for reasons of political feasibility, we assume that the regulator does not want any firms to be driven out of business following the introduction of the scheme. For a utilitarian regulator, the objective function is therefore the sum of firms' expected utility, minus environmental damages, minus transfers to the firms (evaluated at the social price of public funds, $1+\lambda$ ):

$$
n\left(w_{0}+p q-C(q, \boldsymbol{s})-\frac{1}{2} \frac{n-1}{n} \rho \gamma \Sigma_{\epsilon} \gamma^{T}\right)-E(D(\boldsymbol{e}))-n(1+\lambda) w_{0},
$$

subject to the firms' participation and incentive compatibility constraints.

We see immediately that we can use $w_{0}$ to satisfy the participation constraint, and thus that social welfare can be rewritten as: 


$$
n(1+\lambda)\left(p q-C(q, s)-\frac{1}{2} \frac{n-1}{n} \rho \boldsymbol{\gamma} \Sigma_{\epsilon} \boldsymbol{\gamma}^{T}\right)-E(D(\boldsymbol{e}))
$$

Before proceeding, we need to introduce some supplementary notation.

Let $\Pi^{\prime} \equiv\left(\frac{\partial \Pi(.)}{\partial q} \frac{\partial \Pi(\cdot)}{\partial s_{1}} \ldots \frac{\partial \Pi(.)}{\partial s_{J}}\right)$ and $E^{\prime} \equiv\left(0 \frac{\partial E(D(\boldsymbol{e}))(.)}{\partial s_{1}} \ldots \frac{\partial E(D(\boldsymbol{e}))(.)}{\partial s_{J}}\right)$. Let $\left[\Pi^{\prime \prime}\right]$ be the Hessian of the profit function, let $\Pi_{q q}=\frac{\partial^{2} \Pi(.)}{\partial q^{2}}$, let $\Pi_{q s} \equiv$ $\left(\frac{\partial^{2} \Pi(.)}{\partial s_{1} \partial q} \ldots \frac{\partial^{2} \Pi(.)}{\partial s_{J} \partial q}\right)$ and let $\Pi_{s s}$ be the Hessian of the profit function with respect to the emission vector.

$[A]$ is the $J \times(J+1)$ matrix formed by the juxtaposition of a first colum $\Pi_{q q}^{-1} \Pi_{q s}^{T}$ and the $J \times J$ diagonal matrix with diagonal element -1 .

This leads us to the first important result with yardstick competition:

Proposition 1 Suppose that all the standard second order conditions are satisfied. The optimal output and emission levels in a yardstick competition scheme are given by: $(1+\lambda) n\left(\Pi^{\prime}+\frac{n}{n-1} \rho \Pi_{s}^{\prime} \Sigma_{\epsilon}[A]\left[\Pi^{\prime \prime}\right]\right)=E^{\prime}$. The optimal incentive scheme is given by $\Pi_{s}^{\prime}=\frac{n-1}{n} \gamma$.

Proof. The Lagrangian is:

$$
\begin{aligned}
n(1+\lambda)(p q-C(q, s)- & \left.\frac{1}{2} \frac{n-1}{n} \rho \boldsymbol{\gamma} \Sigma_{\epsilon} \boldsymbol{\gamma}^{T}\right)-E(D(\boldsymbol{e})) \\
& +\mu_{q} \frac{\partial \Pi}{\partial q}+\left(\Pi_{s}^{\prime}-\frac{n-1}{n} \boldsymbol{\gamma}\right) \boldsymbol{\mu}^{T} .
\end{aligned}
$$

where $\mu_{q}$ is the Lagrange multiplier associated with (8) and $\boldsymbol{\mu} \equiv\left(\mu_{1} \ldots \mu_{J}\right)$ is the vector of Lagrange multipliers associated with the incentive compatibility constraints (10).

The FOC with respect to $\gamma^{T}$ is:

$$
-(1+\lambda) n \rho \Sigma_{\epsilon} \boldsymbol{\gamma}^{T}-\boldsymbol{\mu}^{T}=0 .
$$

Thus, for $\rho>0$, at least one of the firms' IC constraints must be binding. Hence, (13) simplifies to (using (10)) :

$$
-(1+\lambda) \frac{n^{2}}{n-1} \rho \Pi_{s}^{\prime} \Sigma_{\epsilon}=\boldsymbol{\mu} .
$$

The FOC with respect to the output and the emission vector is:

$$
\left(n(1+\lambda) \Pi^{\prime}-E^{\prime}\right)^{T}+\left[\Pi^{\prime \prime}\right]\left(\mu_{q} \boldsymbol{\mu}\right)^{T}=0
$$


As the FOC for the firm implies $\frac{\partial \Pi(\cdot)}{\partial q}=0$, we immediately obtain that the first line of (15) reduces to:

$$
\Pi_{q q} \mu_{q}+\Pi_{q s} \boldsymbol{\mu}^{T}=0
$$

Substitute (14) in (16):

$$
\Pi_{q q} \mu_{q}=(1+\lambda) \frac{n^{2}}{n-1} \rho \Pi_{s}^{\prime} \Sigma_{\epsilon} \Pi_{q s}
$$

Substitute (17) and (14) in (15):

$$
(1+\lambda) n\left(\Pi^{\prime}+\frac{n}{n-1} \rho \Pi_{s}^{\prime} \Sigma_{\epsilon}[A]\left[\Pi^{\prime \prime}\right]\right)=E^{\prime} .
$$

This condition determines the optimal output and emission levels.

\section{Comments}

1. If the cost function is separable in output and emissions, then $\Pi_{q s}$ is the null vector. It is then easy to verify that the optimal emission levels are given by

$$
E_{s}^{\prime}=n(1+\lambda) \Pi_{s}^{\prime}\left(I_{j}-\frac{n}{n-1} \rho \Sigma_{\epsilon}\left[\Pi_{s s}\right]\right)
$$

where $E_{s}^{\prime} \equiv\left(\frac{\partial E(D(\boldsymbol{e}))(.)}{\partial s_{1}} \ldots \frac{\partial E(D(\boldsymbol{e}))(.)}{\partial s_{J}}\right)$ and $I_{j}$ is the $J \times J$ unit matrix. Thus, in this particular case, the determination of optimal emissions does not depend on the output decision.

2. Suppose (see Holmstrom and Milgrom [8, p. 32]) that the error terms are stochastically independent and that the emissions are technologically independent as well (thus, that $\frac{\partial^{2} \Pi(.)}{\partial s_{j} \partial s_{k}}=0$ if $j \neq k$ ). In that case, the conditions with respect to the emission levels in (18) reduce to:

$$
\frac{\partial E(D(e))(.)}{\partial s_{j}}=n(1+\lambda)\left(1-\frac{n}{n-1} \rho \frac{\partial^{2} \Pi(.)}{\partial s_{j}^{2}} \sigma_{j}^{2}\right)^{-1} \frac{\partial \Pi(.)}{\partial s_{j}},
$$

where $s_{j}^{2}$ is the variance of $\epsilon_{j}$.

Thus, in this case, the problem reduces to $j$ independent one-task problems. However, in general, it is not optimal to ignore the stochastic and technological dependencies between the different types of emissions in designing the yardstick incentive scheme. Or, to put it differently: it is not indicated that different types of pollutants are regulated independently by specialized bureaus. 
3. As noted before, the yardstick incentive scheme is completely independent of the common error term, even if this common error term becomes extremely "diffuse". If there are no idiosyncratic measurement errors, we see that $E^{\prime}=n(1+\lambda) \Pi^{\prime}$ satisfies (18) and thus that yardstick incentive schemes allow to obtain the first best solution however large the variance of the common error - this is a generalization of a result that is well known in one-dimensional context (see for instance Laffont and Tirole [10, p. 85]).

4. If agents are risk-neutral, then $E^{\prime}=n(1+\lambda) \Pi^{\prime}$ satisfies (18). Thus, yardstick incentive schemes allow to obtain the first-best solution when agents are risk neutral. On the other hand, with risk-averse agents, there is a distortion in the relative weights $\gamma$ compared to the principal's marginal benefits.

\section{Pollution Taxes}

The analysis of optimal regulation under pollution taxes is a natural extension of the existing literature. We write it down explicitly for the sake of completeness.

Suppose thus that the regulator imposes a vector of taxes (which is assumed to be uniform across firms): $\boldsymbol{t}=\left(t_{1} \ldots t_{j} \ldots t_{J}\right)$, where $t_{j}$ is the tax on $e_{j}$. A fixed tax (or subsidy) $w_{0}$ is used to satisfy the participation constraint.

Again, let us first turn to the firms' problem.

Firm 1's expected payment is $\boldsymbol{t} \cdot \boldsymbol{s}_{\boldsymbol{i}}$.

Therefore, firm's 1's expected utility is:

$$
p q_{1}-C\left(q_{1}, \boldsymbol{s}_{\mathbf{1}}\right)+w_{0}-\boldsymbol{t} \cdot \boldsymbol{s}_{\mathbf{1}}-\frac{1}{2} \rho \mathbf{t} \Sigma \mathbf{t}^{T} .
$$

where $\mathbf{t} \Sigma \mathbf{t}^{T}$ is the variance of each agent's tax payments.

In a symmetric and interior equilibrium, the FOC are:

$$
\frac{\partial \Pi(.)}{\partial q}=0
$$

and (assuming an interior solution for all emission levels)

$$
\Pi_{s}^{\prime}=\mathbf{t} .
$$

Let us now turn to the regulator's problem. As with yardstick competition, it can easily be verified that the participation constraint bites. After substitution of these constraints, the Lagrangian is (where $\mu_{q}$ is the Lagrange multiplier associated with (20) and $\boldsymbol{\mu} \equiv\left(\mu_{1} \ldots \mu_{j}\right)$ is the vector of Lagrange multipliers associated with (21)):

$$
n(1+\lambda)\left(p q-C(q, s)-\frac{1}{2} \rho \mathbf{t} \Sigma \mathbf{t}^{T}\right)-E(D(\boldsymbol{e}))+\mu_{q} \frac{\partial \Pi(.)}{\partial q}+\left(\Pi_{s}^{\prime}-\boldsymbol{t}\right) \boldsymbol{\mu}^{T}
$$


The FOC with respect to $\mathbf{t}$ is then:

$$
-n(1+\lambda) \rho \Sigma \mathbf{t}^{T}-\boldsymbol{\mu}^{T}=0 .
$$

Of course, if $\rho=0$, this is satisfied for $\mu_{k}=0$ for all $k$.

Substitution of (21) in (23):

$$
-n(1+\lambda) \rho \Pi_{s}^{\prime} \Sigma=\boldsymbol{\mu}
$$

The FOC with respect to output level and the emission vector is :

$$
\left(n(1+\lambda) \Pi_{s}^{\prime}-E^{\prime}\right)^{T}+\left[\Pi^{\prime \prime}\right]\left(\mu_{q} \boldsymbol{\mu}\right)^{T}=0
$$

As the FOC for the firm implies $\frac{\partial \Pi(.)}{\partial q}=0$, we immediately obtain:

$$
\Pi_{q q} \mu_{q}+\Pi_{q s} \boldsymbol{\mu}^{T}=0
$$

Substitution of (24) in (26) yields:

$$
\mu_{q}=\Pi_{q q}^{-1} n(1+\lambda) \rho \Pi_{s}^{\prime} \Sigma \Pi_{q s}^{T}
$$

Combination of (24), (25) and (27) yields the following characterization of the optimal output and emission vector (notice the analogy with (18)): ${ }^{5}$

$$
n(1+\lambda)\left(\Pi^{\prime}+\rho \Pi_{s}^{\prime} \Sigma[A]\left[\Pi^{\prime \prime}\right]\right)=E^{\prime} .
$$

This is compatible with the usual Holmstrom and Milgrom conditions for piece rates [8].

Note that with risk neutral firms and $\lambda=0$, we would obtain the conventional result that marginal benefits should equal marginal external damages.

\section{Comparisons}

Let us now compare the "welfare" properties of unit emission taxes with the yardstick scheme.

Under yardstick competition, social welfare is (substitute the results of Proposition 1 in $(12))$ :

$$
n(1+\lambda)\left(\Pi-\frac{1}{2} \frac{n}{n-1} \rho \Pi_{s}^{\prime} \Sigma_{\epsilon}\left(\Pi_{s}^{\prime}\right)^{T}\right)-E(D(\boldsymbol{e}))
$$

Similarly, under environmental taxation, it is:

\footnotetext{
${ }^{5}$ Again, assuming that all the standard second-order conditions are satisfied as well.
} 


$$
n(1+\lambda)\left(\Pi-\frac{1}{2} \rho \Pi_{s}^{\prime} \Sigma\left(\Pi_{s}^{\prime}\right)^{T}\right)-E(D(\boldsymbol{e}))
$$

Hence, for a given output and emission vector, yardstick competition dominates taxation if:

$$
\Pi_{s}^{\prime} \Sigma\left(\Pi_{s}^{\prime}\right)^{T}>\frac{n}{n-1} \Pi_{s}^{\prime} \Sigma_{\epsilon}\left(\Pi_{s}^{\prime}\right)^{T}
$$

As this inequality is also valid for the output and emission vector that correspond to the optimal yardstick scheme, we obtain immediately:

Proposition 2 Suppose there is no common shock. There always exists a set of unit emission taxes that is Pareto-superior to the optimal yardstick scheme.

Proof. If there is no common shock, then $\Sigma_{\epsilon}=\Sigma$. The proof is then completed by noting that $\frac{n}{n-1}>1$.

This result is a generalization of a result that is well known in a onedimensional setting (see Holmstrom [7, Theorem 7]).

We also obtain:

Proposition 3 There exists a yardstick scheme that dominates unit emission taxes if:

- at least one common error term has a "sufficiently high" variance

- and/or if at least two common error terms show a positive and "sufficiently strong" covariance.

- if the number of firms is sufficiently large, where the critical number of firms is given by: $n>\frac{\Pi_{s}^{\prime} \Sigma\left(\Pi_{s}^{\prime}\right)^{T}}{\Pi_{s}^{\prime} \Sigma_{\eta}\left(\Pi_{s}^{\prime}\right)^{T}}$

This argument is independent of the agents' degree of risk aversion.

Proof. Just note that $\Pi_{s}^{\prime} \Sigma_{\eta}\left(\Pi_{s}^{\prime}\right)^{T}=\sum_{k=1}^{j} \sum_{l=1}^{j} \frac{\partial \Pi(.)}{\partial s_{k}} \frac{\partial \Pi(.)}{\partial s_{l}} \sigma_{k l}^{\eta}$, and remember that the unregulated profit function is increasing in emission levels, so that $\frac{\partial \Pi(.)}{\partial s_{k}}>0$ for all $k$. The proof is completed by observing that (30) is also valid for the output and emission vector that correspond to the optimal unit emission taxes.

Results summed up in Proposition 3 are a consequence of the main theoretical advantage of yardstick schemes, namely their ability to "sort out" of the payment determination common random terms.

The first part of Proposition 3 extends to a multi task setting a result obtained in tournament theory by Green and Stokey [3]. 
On the other hand, the second part of Proposition 3 is a new result, and leads to the conclusion that a positive correlation among common random terms can cause yardstick schemes to be Pareto superior with respect to pollution taxes even if the variance of common measurement errors is low.

Indeed, measurement difficulties affecting all regulated firms in the same way can play a relevant role in determining the performance of environmental policy instruments. Consider, for example, a laboratory working for the environmental regulator, whose main duty is the measurement of the amount of water pollution generated by $n$ regulated firms; the resulting tax payment by firms is then determined by the environmental regulator on the basis of such assessment. In this case, both firms' performance concerning each pollutant is likely to be monitored using the same device (and the same people). In the presence of a high variance in the resulting "common" measurement errors, Proposition 3 suggests that yardstick schemes might be a "socially desirable" environmental policy instrument, as they would "cancel out" the related risk from the payment determination. On the other hand, even if water pollution could be measured inside the laboratory using relatively precise monitoring and/or estimation methodologies, it could be the case that the same device or measurement technique is used to measure the amount of different pollutants; this could, in turn, generate a strong positive covariance among common measurement errors. In this case as well, Proposition 3 suggests the use of relative compensation mechanisms.

A possible alternative interpretation of the error terms is that they represent "true random variations". For example, weather conditions can affect the way different chemicals discharged by regulated firms "translate" into polluted water (or air). If the $n$ regulated firms are subject to the same weather conditions, Proposition 3 suggests that yardstick schemes are likely to dominate taxes. This point remains valid if the firms have multiple plants, as long as they both emit the same type of pollutants at each plant (for instance, because the production process at each plant depends on the proximity of raw materials).

Finally, the impact of the number of firms is new as well. This result can be understood as follows. The advantage of yardstick regulation is that the common error terms disappear, which reduces the variance of the compensation scheme compared to Pigovian taxation. However, the firm's payoffs now depend on the (stochastic) average performance of the other firms, which is a new element of risk. Hence, for a small number of firms, it is possible that this second effect dominates. However, when the number of firms increases, these idiosyncratic terms will cancel out on average due to the law of large numbers, and, in the limit, the additional risk imposed by the industry's performance reduces to zero.

\section{Liability Rules and Environmental Damages: some considerations}

Liability rules for environmental accidents have been proposed as an instrument to control pollution that is alternative to regulation, especially in cases when 
toxic or particularly hazardous substances are involved. Siebert [20] refers to strict liability, implying that who causes an environmental accident has to pay for the damages irrespective of negligence, and to negligence rules, requiring a prescribed level of "due care", so that who causes environmental harm is held liable if the prescribed standard of care has not been applied.

The link between negligence rules and our multitask yardstick schemes is easy to see. Indeed, precautions to avoid accidents often have multi-dimensional features. Furthermore, standards in negligence liability are often based on a relative basis: this is indeed the case when law enforces "...the best practices in industry " [1, p. 315, emphasis added]. In such a way, courts eliminate common shocks (such as industry specific risks) in the determination of negligence standards. Another example of "relative" negligence rules can be found in the so-called "state-of-the-art defense", as it "...creates a relative test of liability..." that "relies almost exclusively on a comparison between the characteristics of the defendants' production process and the characteristics of its competitors' process." $[4, \text { p. } 7]^{6}$. However, in reality, there are cases when neither negligence rules nor yardstick schemes can take all dimensions into account in determining the required standard of care.

Holmstrom and Milgrom [8] have dedicated Section 3 of their analysis to situations where some dimensions of the agent's performance cannot be contracted upon. They have used this framework to explain real-world phenomena such as missing incentive clauses in contracts and "low-powered" incentives in firms. It is straightforward (detailed arguments are available from the authors on request) to verify that the analysis of Holmstrom and Milgrom generalizes completely to yardstick schemes. Therefore, yardstick schemes cannot be used to attenuate this type of problems, and neither do negligence rules, sharing the same underlying logic.

These insights explain a possible reason why the "inability to determine optimal activity levels except in simple cases is potentially a serious shortcoming of a negligence system" [16, p. 193].

Of course, other relevant issues have to be taken into account when dealing with the choice among strict and negligence liability ${ }^{7}$, but the failure of (yardstick schemes and) negligence rules as a way out from situations where some dimensions of performance cannot be contracted upon is an argument in favor of strict environmental liability and, thus, in favor of transferring all risk to the regulated agent. Indeed, under strict liability, the polluter gets the correct incentives concerning activity levels affecting the probability of environmental accidents.

\footnotetext{
${ }^{6}$ For example, under state of the art defense, firms can avoid liability if the production process safety at time of production compared favorably to the customary practices in the industry.

${ }^{7}$ See, for example, [15] for a discussion.
} 


\section{Conclusion}

We have considered environmental regulation of $n$ risk-averse firms, and compared a set of unit emission taxes with a multi-task "yardstick competition" scheme.

Our first conclusion has been that the higher the variance of "common" random terms, the more "socially desirable" will be the "yardstick competition" mechanism we propose. Furthermore, we have shown that, in the presence of a sufficiently strong positive correlation among different common errors, "yardstick competition" Pareto dominates unit emission taxes. Also, if the number of firms grows to infinity, the yardstick system always dominates unit emission taxes. We have also provided insights on "environmental" liability rules, as an alternative to direct pollution regulation, and presented arguments in favor of strict liability.

Of course, this paper could be extended in many ways. For instance, the bulk of the literature of yardstick regulation treats problems of adverse selection rather than moral hazard (see Tangeràs [21] for a recent example). Hence, further insights could be gained from relaxing the assumption of identical and known abatement cost functions for the regulated firms.

Also, it is possible that, in practice, global ambient pollution levels can be measured with a substantially smaller variance (or at a substantially lower cost) than individual pollution levels. In that case, the problems turns into a nonpoint source problem and collective penalty schemes, such as first proposed by Segerson [18], could be optimal. However, a comparison between the schemes proposed here and the Segerson-type mechanism requires a detailed modeling of how individual emissions translate in ambient levels - it is left as area for further research. ${ }^{8}$

Finally, with yardstick competition, there is a risk for collusive behavior. The development of collusion-proof schemes is also the subject of further research by the authors.

\section{References}

[1] Cooter R. and Ulen T. (2000), Law and Economics (3rd edition), AddisonWesley

[2] Govindasamy R., Herriges, J.A., Shogren, J.F (1994), Nonpoint tournaments, in Dosi, C. and Tomasi, T., Nonpoint Source Pollution Regulation: Issues and Analysis, Kluwer Academic Publishers, Dordrecht.

[3] Green, J.R., Stokey, N.L. (1983), "A Comparison of Tournaments and Contracts", Journal of Political Economy 91, 349-364.

\footnotetext{
${ }^{8}$ The authors would like to thank Juan Pablo Montero for suggesting this particular extension.
} 
[4] Hinschenberger, G., Helmer E., Deffains B. "Environmental Liability, State of the Art Defense and Incentives to Innovate", paper presented at the 20th EALE Conference, University Nancy 2 (France), 18-20 September 2003.

[5] Franckx, L., A. D'Amato, and I. Brose, (2004) "Multitask Rank Order Tournaments," Economics Bulletin, Vol. 10 no. 10 pp. 1-10.

[6] Hirshleifer, J., Riley, J.G. (1992), The Analytics of uncertainty and information Cambridge : Cambridge University Press.

[7] Holmstrom, B. (1982), "Moral Hazard in Teams", Bell Journal of Economics, 13, 2 (Autumn), 324-340

[8] Holmstrom, B., Milgrom, P. (1991), "Multitask Principal Agent Analysis: Incentive Contracts, Assets Ownership and Job Design", Journal of Law, Economics and Organization 7, 24-52

[9] Laffont, J.J., Tirole, J. (1986), "Using Cost Observation to Regulate Firms", Journal of Political Economy 94, 614-641.

[10] Laffont, J-J and Tirole, J. (1993), A Theory of Incentives in Procurement and Regulation, MIT Press, Cambridge, Massachussets.

[11] Lazear, E.P. (1995), Personnel Economics, MIT Press.

[12] Lazear, E.P., Rosen, S. (1981) "Rank Order Tournaments as Optimum Labor Contracts", Journal of Political Economy 89, 841-864.

[13] Malcomson, J.M. (1984), "Work Incentives, Hierarchy, and Internal Labor Markets", Journal of Political Economy, 92, 486-507

[14] Mookherjee, D. (1984), Optimal Incentive Schemes with Many Agents", Review of Economic Studies, LI, 433-446

[15] Polinsky, A. M., Shavell, S. (2000) "The Economic Theory of Public Enforcement of Law", Journal of Economic Literature, 38, 45-76.

[16] Posner, R.A. (1998), Economic analysis of law (5th edition), Aspen Law \& Business, New York.

[17] Prendergast C. (1999) "The Provision of Incentives in Firms", Journal of Economic Literature 37, 7-63.

[18] Segerson, K. (1988), "Uncertainty and Incentives for Non-point Pollution Control," Journal of Environmental Economics and Management, 15, 1, 87-98.

[19] Shleifer, A. (1985), "A theory of yardstick competition", Rand Journal of Economics, 16, 319-27.

[20] Siebert, H. (1998), Economics of the Environment (5th edition), SpringerVerlag, Berlin. 
[21] Tangeràs (2002), "Collusion-proof yardstick competition", Journal of Public Economics, 83, 231-254 
The Center for Economic Studies (CES) is the research division of the Department of Economics of the Katholieke Universiteit Leuven. The CES research department employs some 100 people. The division Energy, Transport \& Environment (ETE) currently consists of about 15 full time researchers. The general aim of ETE is to apply state of the art economic theory to current policy issues at the Flemish, Belgian and European level. An important asset of ETE is its extensive portfolio of numerical partial and general equilibrium models for the assessment of transport, energy and environmental policies.

\section{ETE WORKING PAPER SERIES 2004}

$N^{\circ} 2004-16$

N²004-15

$N^{\circ} 2004-14$

$N^{\circ} 2004-13$

$N^{\circ} 2004-12$

N²004-11

$\mathrm{N}^{\circ} 2004-10$

N²004-09

N²004-08

N²004-07

N²004-06

$n \circ 2004-05$

$n^{\circ} 2004-04$
Franckx L, D'Amato A., Brose I. (2004), Multi Pollutant Yardstick Schemes as Environmental Policy Tools

Rousseau S., Proost S. (2004), The Relative Efficiency of Marketbased Environmental Policy Instruments with Imperfect Compliance

Eyckmans J., Finus M. (2004), An Almost Ideal Sharing Scheme for Coalition Games with Externalities

De Borger B., Mayeres I. (2004), Taxation of car ownership, car use and public transport: insights derived from a discrete choice numerical optimisation model

De Borger B., Proost S. (2004), Vertical and horizontal tax competition in the transport sector

de Palma A., Dunkerley F., Proost S. (2004), Imperfect Competition and Congestion in a City with asymmetric subcenters

Calthrop E., Proost S. (2004), Regulating on-street parking

de Palma A., Proost S. (2004) Imperfect competition and congestion in the City

Pepermans G., Willems B. (2004), Ramsey Pricing in a Congested Network with Market Power in Generation: A Numerical Illustration for Belgium

Delhaye E. (2004), Traffic safety: speed limits, strict liability and a km tax

Eyckmans J., Finus M. (2004), An Empirical Assessment of Measures to Enhance the Success of Global Climate Treaties

Eyckmans J., Meynaerts E., Ochelen S. (2004), The Environmental Costing Model: a tool for more efficient environmental policymaking in Flanders

Saveyn B., Proost S. (2004), Environmental Tax Reform with Vertical Tax Externalities in a Federal State 